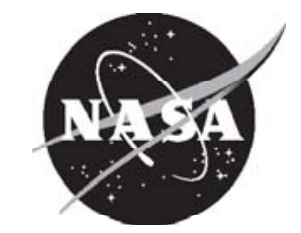

\title{
Unsteady Analysis of Blade and Tip Heat Transfer as Influenced by the Upstream Momentum and Thermal Wakes
}

\author{
Ali A. Ameri \\ The Ohio State University, Columbus, Ohio \\ David L. Rigby \\ ASRC Aerospace Corporation, Cleveland, Ohio \\ Erlendur Steinthorsson \\ A \& E Consulting, Westlake, Ohio \\ James D. Heidmann and John C. Fabian \\ Glenn Research Center, Cleveland, Ohio
}




\section{NASA STI Program . . . in Profile}

Since its founding, NASA has been dedicated to the advancement of aeronautics and space science. The NASA Scientific and Technical Information (STI) program plays a key part in helping NASA maintain this important role.

The NASA STI Program operates under the auspices of the Agency Chief Information Officer. It collects, organizes, provides for archiving, and disseminates NASA's STI. The NASA STI program provides access to the NASA Aeronautics and Space Database and its public interface, the NASA Technical Reports Server, thus providing one of the largest collections of aeronautical and space science STI in the world. Results are published in both non-NASA channels and by NASA in the NASA STI Report Series, which includes the following report types:

- TECHNICAL PUBLICATION. Reports of completed research or a major significant phase of research that present the results of NASA programs and include extensive data or theoretical analysis. Includes compilations of significant scientific and technical data and information deemed to be of continuing reference value. NASA counterpart of peer-reviewed formal professional papers but has less stringent limitations on manuscript length and extent of graphic presentations.

- TECHNICAL MEMORANDUM. Scientific and technical findings that are preliminary or of specialized interest, e.g., quick release reports, working papers, and bibliographies that contain minimal annotation. Does not contain extensive analysis.

- CONTRACTOR REPORT. Scientific and technical findings by NASA-sponsored contractors and grantees.

- CONFERENCE PUBLICATION. Collected papers from scientific and technical conferences, symposia, seminars, or other meetings sponsored or cosponsored by NASA.

- SPECIAL PUBLICATION. Scientific, technical, or historical information from NASA programs, projects, and missions, often concerned with subjects having substantial public interest.

- TECHNICAL TRANSLATION. Englishlanguage translations of foreign scientific and technical material pertinent to NASA's mission.

Specialized services also include creating custom thesauri, building customized databases, organizing and publishing research results.

For more information about the NASA STI program, see the following:

- Access the NASA STI program home page at http://www.sti.nasa.gov

- E-mail your question via the Internet to help@ sti.nasa.gov

- Fax your question to the NASA STI Help Desk at 301-621-0134

- Telephone the NASA STI Help Desk at 301-621-0390

- Write to: NASA Center for AeroSpace Information (CASI) 7115 Standard Drive Hanover, MD 21076-1320 


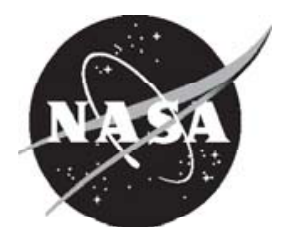

\section{Unsteady Analysis of Blade and Tip Heat Transfer as Influenced by the Upstream Momentum and Thermal Wakes}

Ali A. Ameri

The Ohio State University, Columbus, Ohio

David L. Rigby

ASRC Aerospace Corporation, Cleveland, Ohio

Erlendur Steinthorsson

A \& E Consulting, Westlake, Ohio

James D. Heidmann and John C. Fabian

Glenn Research Center, Cleveland, Ohio

Prepared for the

Turbo Expo 2008 Gas Turbine Technical Congress and Exposition sponsored by the American Society of Mechanical Engineers

Berlin, Germany, June 9-13, 2008

National Aeronautics and

Space Administration

Glenn Research Center

Cleveland, Ohio 44135 
This work was sponsored by the Fundamental Aeronautics Program at the NASA Glenn Research Center.

Level of Review: This material has been technically reviewed by technical management.

Available from

NASA Center for Aerospace Information 7115 Standard Drive

Hanover, MD 21076-1320
National Technical Information Service 5285 Port Royal Road Springfield, VA 22161

Available electronically at http://gltrs.grc.nasa.gov 


\title{
Unsteady Analysis of Blade and Tip Heat Transfer as Influenced by the Upstream Momentum and Thermal Wakes
}

\author{
Ali A. Ameri \\ The Ohio State University \\ Columbus, Ohio 43210 \\ David L. Rigby \\ ASRC Aerospace Corporation \\ Cleveland, Ohio 44135 \\ Erlendur Steinthorsson \\ A \& E Consulting \\ Westlake, Ohio 44140
}

James D. Heidmann and John C. Fabian

National Aeronautics and Space Administration

Glenn Research Center

Cleveland, Ohio 44135

\begin{abstract}
The effect of the upstream wake on the blade heat transfer has been numerically examined. The geometry and the flow conditions of the first stage turbine blade of GE's $\mathrm{E}^{3}$ engine with a tip clearance equal to 2 percent of the span was utilized. Based on numerical calculations of the vane, a set of wake boundary conditions were approximated, which were subsequently imposed upon the downstream blade. This set consisted of the momentum and thermal wakes as well as the variation in modeled turbulence quantities of turbulence intensity and the length scale. Using a one-blade periodic domain, the distributions of unsteady heat transfer rate on the turbine blade and its tip, as affected by the wake, were determined. Such heat transfer coefficient distribution was computed using the wall heat flux and the adiabatic wall temperature to desensitize the heat transfer coefficient to the wall temperature. For the determination of the wall heat flux and the adiabatic wall temperatures, two sets of computations were required. The results were used in a phase-locked manner to compute the unsteady or steady heat transfer coefficients. It has been found that the unsteady wake has some effect on the distribution of the time averaged heat transfer coefficient on the blade and that this distribution is different from the distribution that is obtainable from a steady computation. This difference was found to be as large as 20 percent of the average heat transfer on the blade surface. On the tip surface, this difference is comparatively smaller and can be as large as four percent of the average.
\end{abstract}

\section{Nomenclature}

$\begin{array}{ll}C & \text { axial chord } \\ K & \text { reference thermal conductivity }\end{array}$

$\begin{array}{ll}\mathrm{Nu} & \text { Nusselt Number }=h C / K \\ P & \text { pressure } \\ Q & \text { heat flux (nondimensionalized by } K_{0} T_{0} / C \\ R & \text { local radius } \\ S & \begin{array}{l}\text { wetted distance along the blade, positive on the } \\ \text { suction side and negative on the pressure side }\end{array} \\ T & \begin{array}{l}\text { temperature normalized by the inlet free-stream } \\ \text { absolute temperature }\end{array} \\ T u & \text { turbulence intensity } \\ h & \text { heat transfer coefficient }=q_{w} /\left(T_{a w}-T_{w}\right) \\ n & \text { number of vanes per row } \\ q & \text { wall heat flux } \\ t & \text { time } \\ \theta & \text { local tangential angle } \\ \tau & \text { time period for one wake passage }\end{array}$

\section{Subscripts}

0 absolute total value

a adiabatic

amp amplitude

bg background value

w wall value

$x \quad$ axial value

\section{Introduction}

Improvements in the accuracy of computations of heat transfer at the interface of turbine blade with the hot gases are essential to the design of enhanced turbine components. As turbine flows are unsteady, the question arises as to whether unsteady computations would add information that would contribute to the accuracy of the computations. This is nearly impossible to ascertain experimentally as the equivalent steady 
conditions are very difficult to configure in a turbine rig. The differences in the results of unsteady and steady computations are however possible to assess and decide if the significant expenditure of additional resources would be justified. Such unsteady computations can be made in various modes. The most practical of them is the use of Unsteady ReynoldsAveraged Navier-Stokes (URANS) analysis, which has been used here. Such models are closed using a turbulence model. The additional assumption made is that these models do in fact represent the mutual effect of flow and turbulence by treating the turbulence variables as time dependent (adding a $d / d t$ term) without any additional modeling.

In an earlier paper, Ameri et al. (ref. 1), computed the surface and tip heat transfer coefficient for rotating blades of the first stage high-pressure turbine of $G E-E^{3}$. We made several simplifications to facilitate the computations. We assumed that the number of vanes is the same as the number of blades. We assumed a one way coupling between the stator and rotor through the use of 'gust' boundary conditions. In doing so, we neglected the thermal wake (and the hot streaks from the upstream combustor). We explored the 1:1 vane/blade simplification in a preliminary study that showed little difference in the time mean heat transfer between a $1: 1$ and 2:3 vane/blade count and thus found the average heat transfer not to be sensitive to this ratio in the range studied. As for the inlet total pressure upstream of the rotor used in the gust boundary condition, we computed the flow through the vane passage apriori to obtain the total pressure distribution downstream of the vane. Fitting an approximate analytical function of time and location to describe the variation, we used this function to prescribe the total absolute inlet pressure. We computed the heat transfer coefficient for the blade and found some differences between the average of unsteady computation of heat transfer and a steady computation of heat transfer based on mean conditions. The differences which were mainly concentrated near the tip of the blade on the suction side were highlighted. No appreciable difference in heat transfer was found on the blade tip.

In this paper, we continue our simplifying assumptions but we improve the computations in two ways. First, we include the thermal wake behind the vanes in addition to the momentum wake and second, we compute the adiabatic wall temperature and compute the 'true' heat transfer coefficient. The heat transfer coefficient thus computed would be independent of the wall temperature which is not uniform on the actual blade surfaces. If we were to perform a conjugate heat transfer analysis, no further external flow computations would be necessary and the heat transfer coefficient and the adiabatic wall temperature would be all that is needed. Of course, this is true as long as no film cooling is being performed.

Review of the literature on unsteady RANS calculations including the rotor/stator interaction would reveal the work of Rao et al. (ref. 2) who used a 2 to 3 vane to stator blade count and a two-dimensional code to simulate the unsteady pressure and heat transfer. In fact the experimental work, which was carried further to different vane/blade spacings, reported by Dunn et al. (ref. 3) was specifically designed with 45 rotor blades and 30 stator blades to provide a data base for numerical verification. Most turbine data come from rigs which are not as forgiving to CFD methods. In the absence of such convenience, Michelassi et al. (ref. 4) rescaled the blade to maintain a one to one ratio of the vane-blade count and used a three-dimensional methodology to calculate the blade heat transfer. Abhari et al. (ref. 5) used the two-dimensional code UNSFLO which uses a transformed Euler scheme to accommodate the vane to blade count ratio to compute the rotor stator interaction in a quasi-three-dimensional manner. The viscous layer was computed using a thin layer approximation and an algebraic turbulence model was used. Dunn et al. (ref. 3) studied the effect of vane/blade spacing on both the vane and blade for three different spacings. The study was performed for the mid span. They measured the unsteady heat flux and computed the same using a two-dimensional computer program UNSFLO.

In reference 6, Ameri et al. used a simple analysis to determine the effect of wake unsteadiness on a 'sliver' of the blade without accounting for the three dimensional effects. They found no appreciable difference between the timeaveraged blade heat transfer and the blade heat transfer obtained using a steady analysis. It was also found that quasisteady analysis of the blade without the effect of rotation leads to erroneous results with respect to the unsteady envelope of heat transfer. Surprisingly, the average thus computed did not differ appreciably from the time mean or steady values.

There are many experimental works which measure the unsteady blade passage heat transfer aside from the measurements done in various works by Dunn et al. as mentioned above. For example, Denos et al. (ref. 7) and Chana

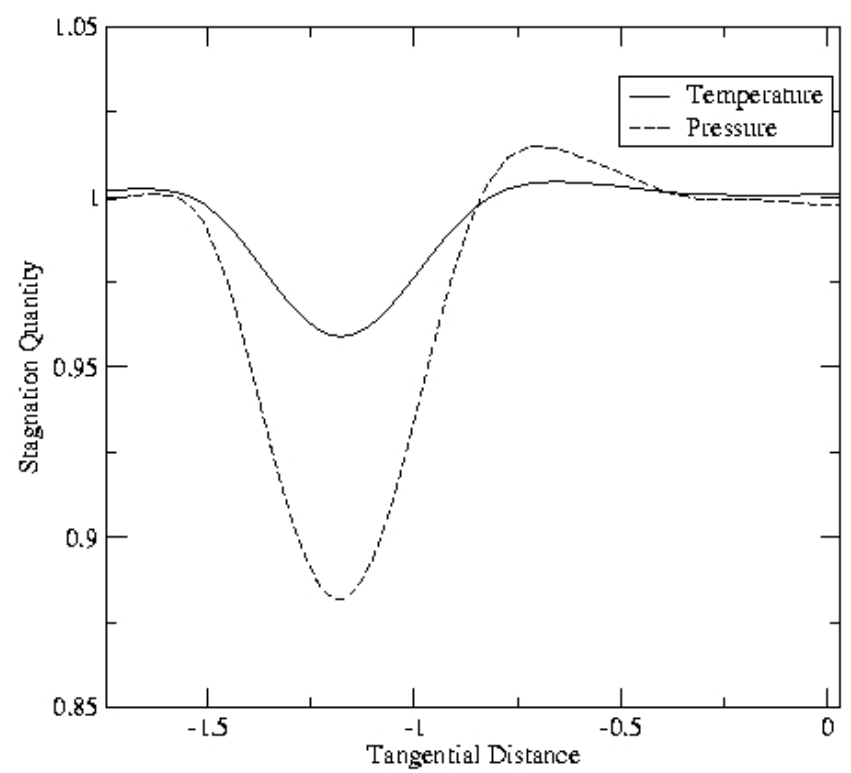

Figure 1.-Total pressure and total temperature at the exit boundary of the guide vane. 
et al. (ref. 8) have made heat transfer measurements in a rotating stage. The former has made heat transfer measurements on the blade surface and has considered the effect of rotation rate while in the latter the effect of cooling of the vane on the rotor blade heat transfer has been examined. The increase in the rotation rate in reference 7 is shown to advance the location of transition upstream on the rotor blade suction surface and increase the level of heat transfer on the pressure side. This could be due to increased buffeting by the wake or due to a change in the relative inlet angle, although, the latter possibility has been rejected in reference 7 .

In the present paper, as with reference 1, we have examined the issue of unsteady heat transfer in high pressure turbine blade passages as related to passing of upstream wakes. The wake has a deficit in total pressure and temperature and as well, possesses a wake-like profile of turbulence intensity and length scale. The variation in total temperature typical of cooled vanes has been included in this paper as it was absent from reference 1. A numerical experiment is presented that compares the time mean heat transfer, computed with an unsteady analysis method against computations of and heat transfer using a simpler steady analysis. The difference will reveal the error incurred by not taking the unsteadiness into account by means of a steady computation.

\section{Computational Preliminaries}

The computer code used for this study was GlennHT2000. The numerical procedure uses a finite-volume discretization scheme that is second order accurate in time and space. An implicit time marching scheme is implemented using subiterations. The turbulence model used for the calculations was the Low Reynolds number $k-\omega$ model of Wilcox (ref. 9) which integrates to the walls (i.e., without the use of wall-functions). The grid used was quite fine adjacent to the blade (maximum value of $y^{+}<1$ ) in the boundary layer. The turbulence model is able to produce an effect similar to the transition from laminar to turbulent flow. In practice, however, the transition is not guaranteed to be in the appropriate location. In fact it is often triggered very near the leading edge which is what occurred in our computations making them turbulent except near the stagnation line. Further details about the code may be found in Ameri et al. (ref. 10). The present version of the computer code is fully parallelized and uses Message Passing Interface (MPI) for parallel processing. The three-dimensional cases were run on 48 processors of a 98 processor Xeon Linux Cluster.

\section{The Geometry and Conditions}

The geometry and the flow conditions of the first stage turbine blade of GE's $E^{3}$ engine (refs. 11 and 12) have been used to obtain the unsteady three-dimensional blade and tip heat transfer. The blade was rotating at $8400 \mathrm{rpm}$. The pressure ratio across the rotor blade based on the stage total pressure was 2.27. There were 76 blades and 46 vanes or a blade-vane ratio of 1.65 . The tip clearance was 2 percent of the blade span. The blade heat transfer was previously computed in references 10 and 12. The numerical scheme has been experimentally validated for tip heat transfer computations in references 13 and 14 .

The effect of the upstream wake of the first-stage vane on the blade heat transfer and pressure was simulated. The vane flow was computed separately as will be described below.

\section{Vane Computation and the Wake Shape}

The guide vane flow was computed using the same code in steady mode. The pressure ratio was 0.59 at the hub. A specific heat ratio of 1.36 was used for the stage. The wall temperature was specified as 0.7 times the inlet total temperature to make the conditions representative of the actual flow conditions. The total pressure and temperature thus computed are shown in figure 1. The total pressure in the wake thus produced was approximated with a trigonometric function as follows

$$
P_{0}(t, \theta)=P_{0-b g}\{1.0-0.15[\sin (n \theta / 2+\pi t / \tau)] 10\}
$$

Where the subscript of $b g$ designates the background value which is a function of radial position only. As for the thermal wake behind the vane the expression used was

$$
T_{0}(t, \theta)=T_{0-b g}\{1.0-0.05[\sin (n \theta / 2+\pi t / \tau)] 10\}
$$

The wake turbulence and length scale were also fitted with trigonometric functions and specified at the inlet. The background level for turbulence intensity was 2 percent and the amplitude was 3 percent for a peak value of 5 percent, i.e.,

$$
T u(t, \theta)=T u_{b g}+T u_{\text {amp }}[\sin (n \theta / 2+\pi t / \tau)] 6
$$

The same applies to the length scale with a background level of $0.01^{*} \mathrm{Cx}$ and a peak of $0.025^{*} \mathrm{Cx}$. The average inlet turbulence was computed to be 2.6 percent with an average length scale of $0.015 \mathrm{Cx}$. It should be noted the turbulence intensity as specified at the inlet is a fraction of absolute free stream velocity. As a fraction of the relative velocity, the average inlet turbulence level is about 7 percent. This is because, at the midspan, the inlet absolute velocity approaches the blade at $75^{\circ}$ and the relative velocity's approach is at approximately $45^{\circ}$ thus yielding 2.7 as the ratio of the absolute velocity to the relative velocity.

\section{Further Simplifications}

To reduce the cost of the computations, a wake passing frequency corresponding to a one to one vane blade ratio was 
used. This simplification was based upon a separate preliminary study reported in reference 1 which showed that for the purposes of average heat transfer the wake frequency for a $1: 1$ ratio and $2: 3$ ratio yield the same average heat transfer. The vane to blade ratio for the actual engine was $46 / 76$ which is close to the $2: 3$ ratio studied.

\section{The Grid}

Figure 2 shows the blade and hub endwall surface as represented by the grid used for the three dimensional computations performed in this work. The grid contained 164 blocks and had a total of 1.8 million nodes. There are 65 nodes across the tip gap in the radial direction. The grid density from the hub to the tip was 101 nodes. An unstructured grid topology with individual structured blocks was used. This offers the flexibility of refining the grid locally as needed without unduly refining the grid in areas where such refinement is unnecessary. The grid density was arrived at after running exploratory computations similar to those already mentioned in the last section. The grid was deemed sufficiently refined when able to support a wake without it dissipating. A dimensionless time step of .005 was used after comparing results using time steps of $0.001,0.0025,0.005$ and 0.01 . The results showed that the time histories for the first three time steps were identical, while the larger 0.01 deviated from that time history. The larger time step of 0.005 also resulted in fewer total subiterations and faster convergence. For the time step size there were 320 time steps required to cover the passing of a wake across a single blade passage.

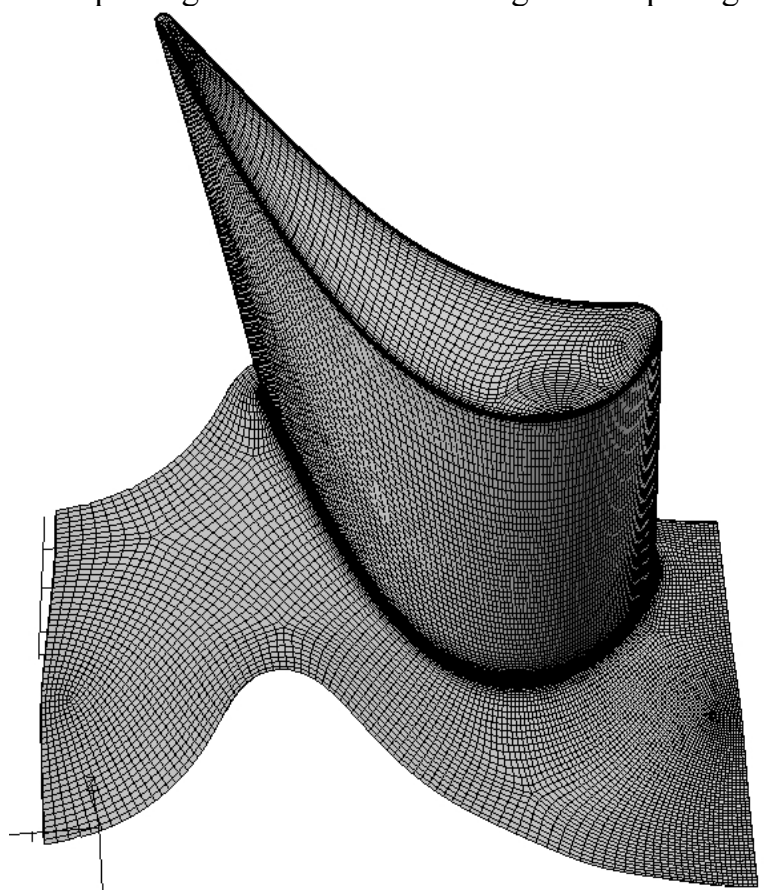

Figure 2.-Grid on blade hub and blade surfaces.

\section{Results and Discussion}

\section{Blade Surface Heat Transfer}

\section{Unsteady Heat Transfer}

In figure 3, we have shown the unsteady variation of heat transfer rate in the form of normalized heat flux on the blade surface. We have shown four different snapshots within a period of a wake-passing going from left to the right and repeating again. On the suction side (top row), a large patch of high heat transfer continuously moves downstream on the surface. Time periodic behavior is also apparent near the hub and on the tip of the blade. On the pressure side (bottom row), the periodic behavior is again apparent. A low heat transfer patch starts upstream, moves downstream, and spreads. Still farther in time, it retracts and reduces to the small area upstream. There is obviously, an unsteady variation in blade heat transfer. The question is whether this variation is, on the average, important.

Recently, in reference 1, we computed the unsteady rate of heat transfer for the present configuration as influenced by the vane's momentum wake. We did not include the effect of the thermal wake. We found that the unsteady effect, on the blade, as measured by the percent difference between the average of the unsteady and equivalent steady conditions on the blade surface was somewhat significant but not on the tip. In the present computations, we have included the thermal wake. We have here computed the heat transfer coefficient using the adiabatic wall temperature to gauge the effect of the thermal wake on the heat transfer coefficient. This has been for the case of no-thermal wake (momentum wake, only) and with the thermal wake. In order to compute the heat transfer coefficient two separate calculations were performed. In the first one a constant temperature boundary condition of $T_{w}=0.7$ was used. From this, the wall heat flux was computed. In order to compute the heat transfer coefficient, which would be independent of the wall temperature and sensitive to the local "bulk" temperature, the adiabatic wall temperature was computed. This was accomplished by setting the wall heat flux to zero and computing the wall temperature. Heat flux along with the adiabatic wall temperature and the heat transfer coefficient are averaged and presented below.

In figures 4 to 12 which present the blade surface results, we have shown both the suction side and the pressure side of the blade and variables are plotted along the distance over the blade surface measured from the minimum axial distance. Positive side is the suction side and negative side is the pressure side. The radial direction is the ordinate.

To start, in figures 4 to 6 the no-thermal wake case in reference 1 is revisited and the adiabatic temperature and Nusselt evaluated and presented. 


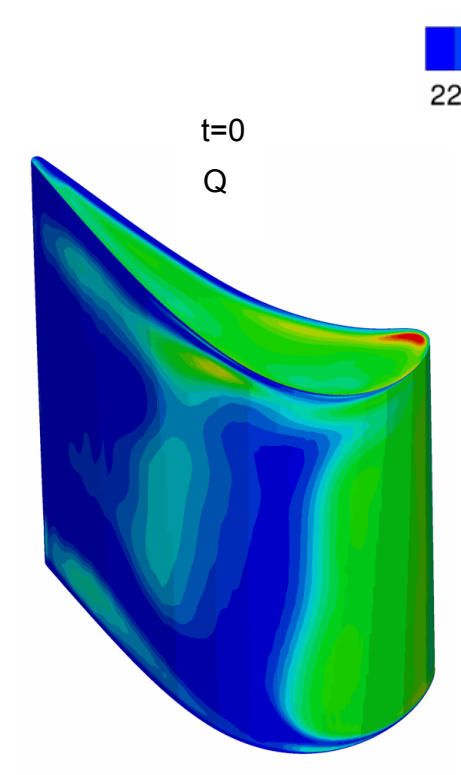

$t=0$

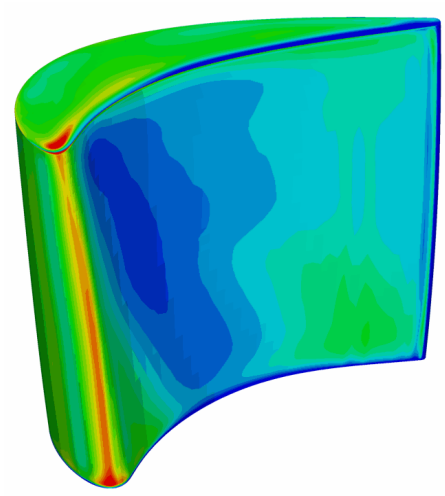

225250275300325350375400425450475500525550575600625 $\mathrm{t}=\mathrm{T} / 4$

$\mathrm{t}=\mathrm{T} / 2$

$t=3 / 4 T$

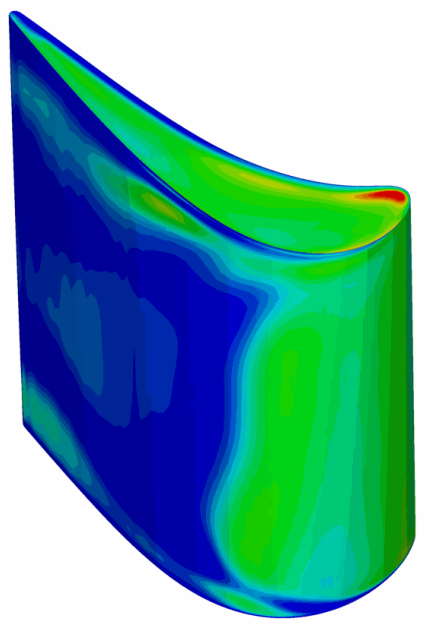

$\mathrm{t}=\mathrm{T} / 4$

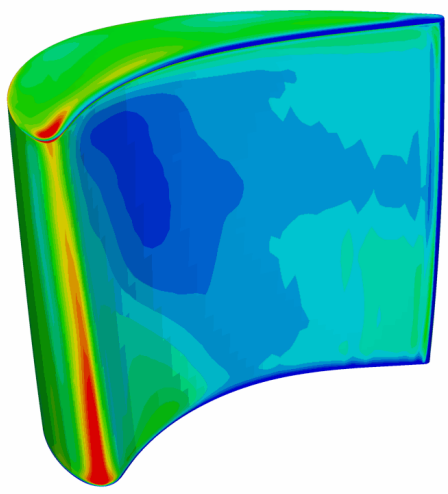

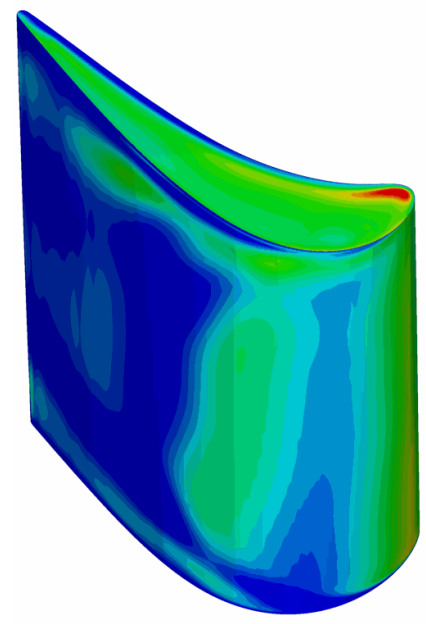

$\mathrm{t}=\mathrm{T} / 2$

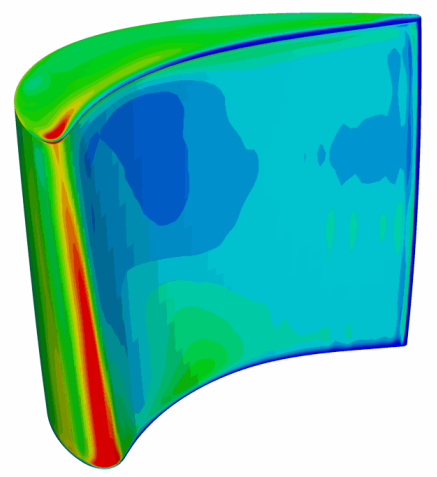

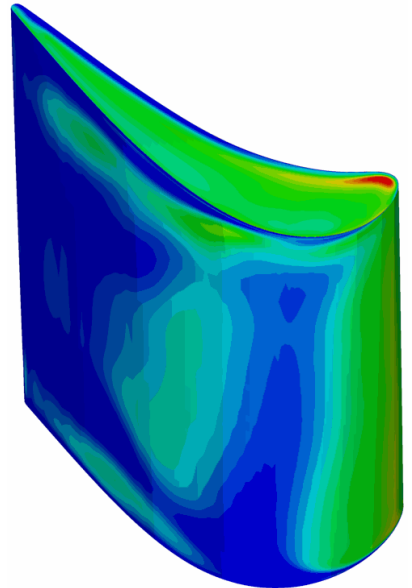

$t=3 / 4 T$

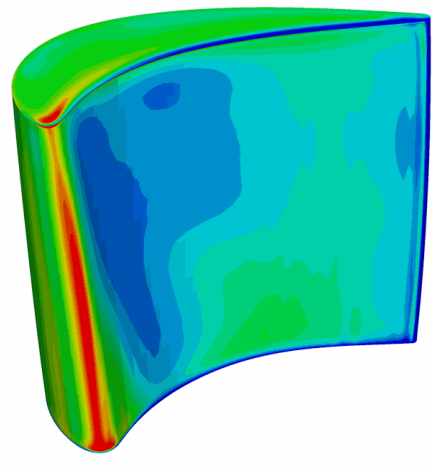

Figure 3.-Blade surface heat flux at four equally spaced times in a period of wake passing. Suction side, top row, and pressure side, bottom row.

Figure 4 present the average heat flux. As expected, the heat flux is the largest around the leading edge, near the tip where the tip clearance vortex is active and on the pressure side near the tip where the "sink" effect is most pronounced. Figure 5, shows the time average of the adiabatic wall temperature. It is interesting to observe that on the suction side, near the tip, the adiabatic wall temperature (fig. 5) is as high as (or even higher) than the value observed near the hub and around the leading edge. At this location near the tip, $T_{a w}$ is the highest on the blade. This is because the fluid flowing along that part of the blade passage has gone over the tip and has not done any work, thus maintaining a total temperature that is near the absolute stage total temperature. This would lead to elevated wall temperatures that would need to be accounted for in the thermal management of the blade. Computed also is the heat transfer coefficient. The unsteady wall heat flux and the unsteady local adiabatic wall temperature which are in phase, with respect to the inlet wake are used to compute the heat transfer coefficient.

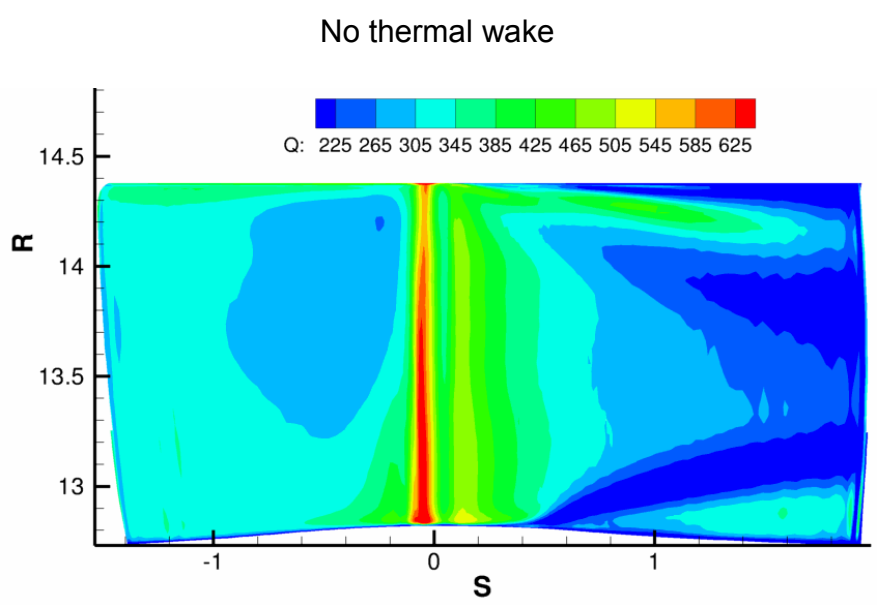

Figure 4.-Distribution of average wall heat flux on the blade surface. 


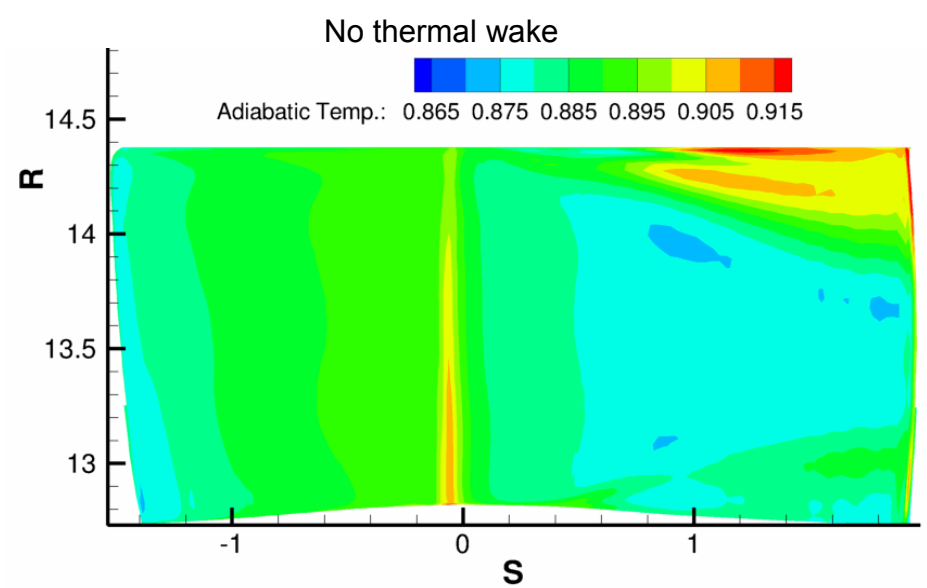

Figure 5.-Distribution of the average adiabatic wall temperature over the blade surface.

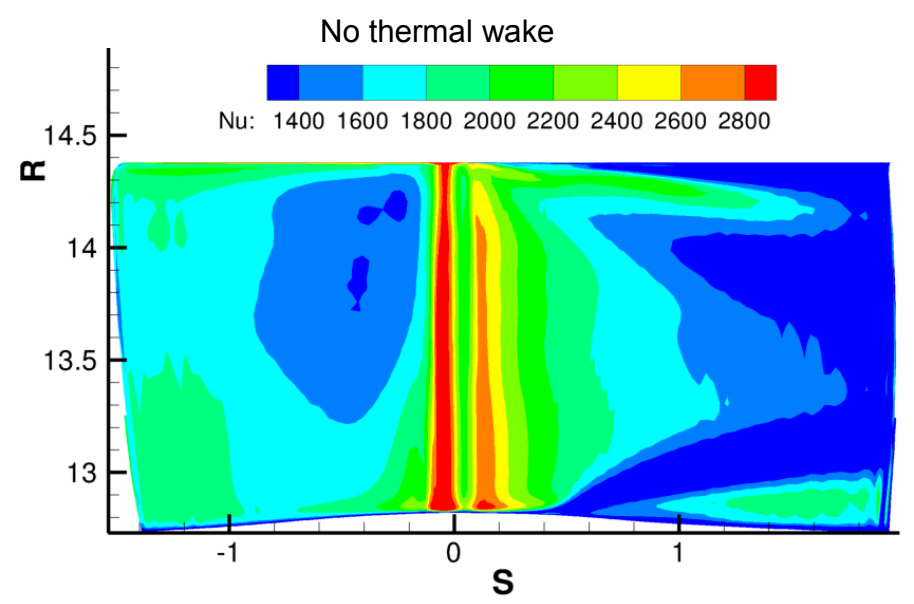

Figure 6.-Average heat transfer coefficient distribution over the blade surface.

$$
h=Q_{w} /\left(T_{w}-T_{a w}\right)
$$

Heat transfer coefficient, nondimensionalized in the form of Nusselt number, is shown in figure 6. It was computed by averaging the Nu over a wake-passing period.

The plots of the computations that result from the momentum and thermal wakes are shown in figures 7, 8, and 9. The heat flux and the adiabatic wall temperature are commensurately lower than the case without the thermal wake. The heat transfer coefficient however is unchanged as might be expected due to the proper scaling.

Experimentally, it has been shown by Chana et al. (ref. 8) that the presence of the thermal wake resulting from cooling the vane surface, leads to a reduction of blade surface heat transfer. This they explain is caused by a reduction of the 'bulk temperature'. They do not present the effect of the thermal wake in terms of Nusselt number but, the unscaled thermal flux of figures 4 and 7 agree with that conclusion.

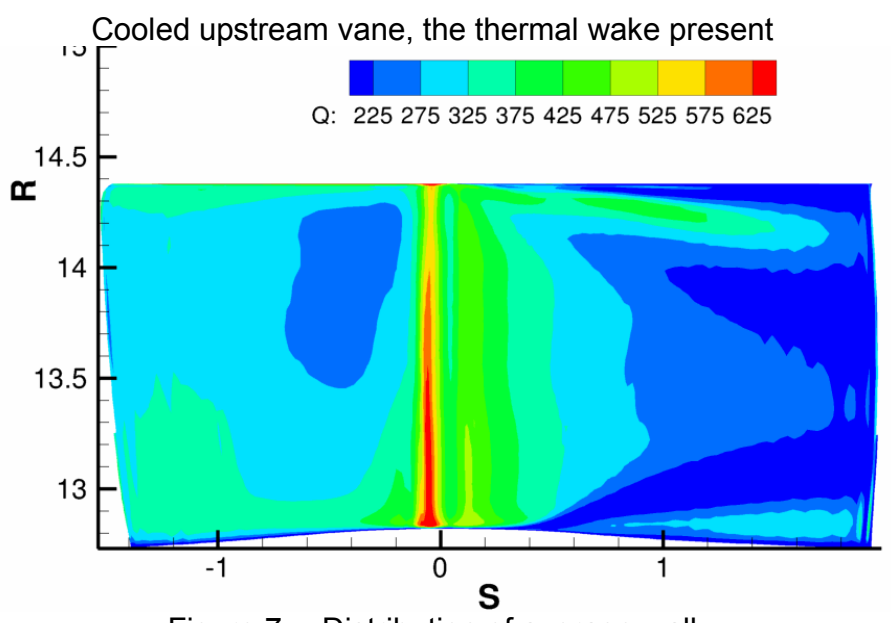

Figure 7.-Distribution of average wall heat flux on the blade surface.

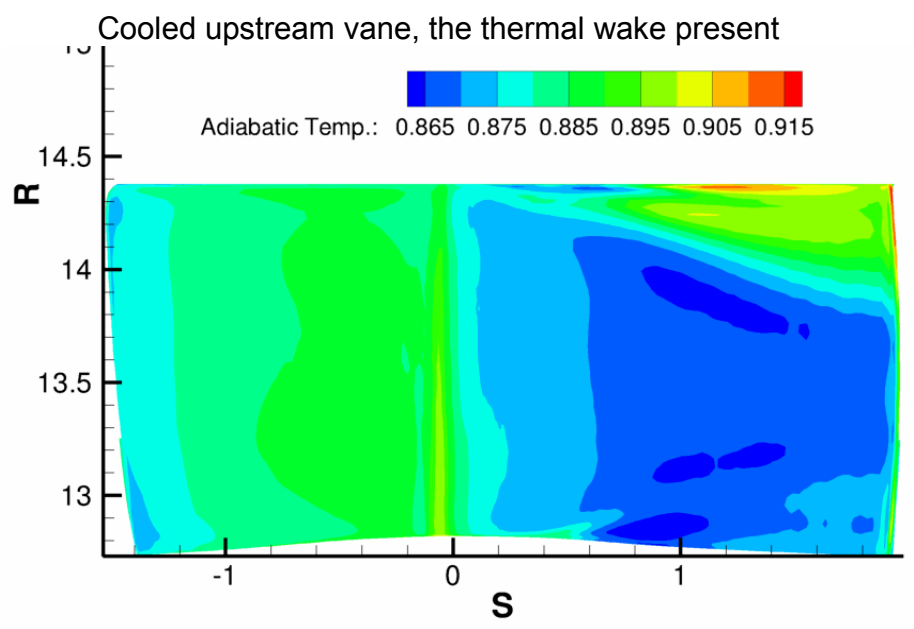

Figure 8.-Distribution of the average adiabatic wall temperature over the blade surface.

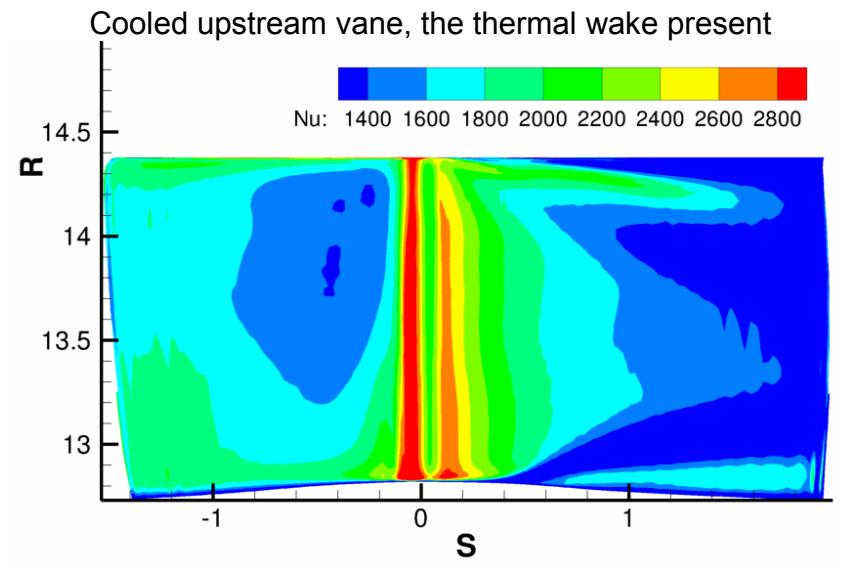

Figure 9.-Average heat transfer coefficient distribution over the blade surface. 


\section{Steady Flow Conditions}

The results derived from the unsteady computations are now compared with those from a set of steady computations. Again, two computations were made. One using an adiabatic boundary condition to isolate the external flow effects and the second to compute the wall heat flux at a fixed wall temperature. To make the conditions equivalent, the inlet total pressure and total temperature averages, over a wake passing period, were computed from the wake profiles and assigned as inlet conditions to the steady computations. Instead of presenting the results of the steady computations, the differences between the steady and the unsteady computations will be shown.

\section{Difference Between Unsteady and Steady Computations}

Figure 10 shows the percent difference in the heat flux between the average of the unsteady wall heat flux and the steady heat flux. The differences are similar to that reported in reference 1 . The difference in the adiabatic wall temperature is shown in figure 11. The difference appears to be small as a percentage of the average of the unsteady adiabatic temperature. The difference in Nusselt number based on the heat transfer coefficient defined in equation (4) is presented in figure 12 . The picture is very much similar to what was shown in reference 1 . The large difference near the leading edge was attributed to the differences in the start of transition which occurs somewhat earlier with the wake induced unsteadiness. This difference in the leading edge heat transfer and to a lesser extent on the pressure side of the blade was eliminated in reference 1 by adjusting the turbulence intensity upwards, namely, from an average of 2.6 to 3 percent. The difference in the heat transfer in other areas were not affected by the adjustment in turbulence intensity. The largest difference was shown to be near the tip on the suction side. As shown in figure 12, the difference in the Nusselt number is as much as 20 percent on the suction side near the tip. On the pressure side, this difference is up to 8 percent which was consistently higher than the steady results. This agrees with the results of Denos et al. (ref. 7) which show increase in the pressure side heat transfer with increase in the rotation rate. This may be attributable to an increase in turbulence level if not due to a net change in the inlet relative angle. On the suction side, there are areas of negative difference but, they are matched with positive areas and thus represent a shift and not a net change. It is also interesting to note that the variation in the heat transfer coefficient correlates very well with the changes in the wall heat flux and thus the differences in the adiabatic wall temperature are not significant.

\section{Tip Heat Transfer}

\section{Unsteady Average}

The time average of unsteady tip heat transfer measured by the normalized heat flux, adiabatic wall temperature and the

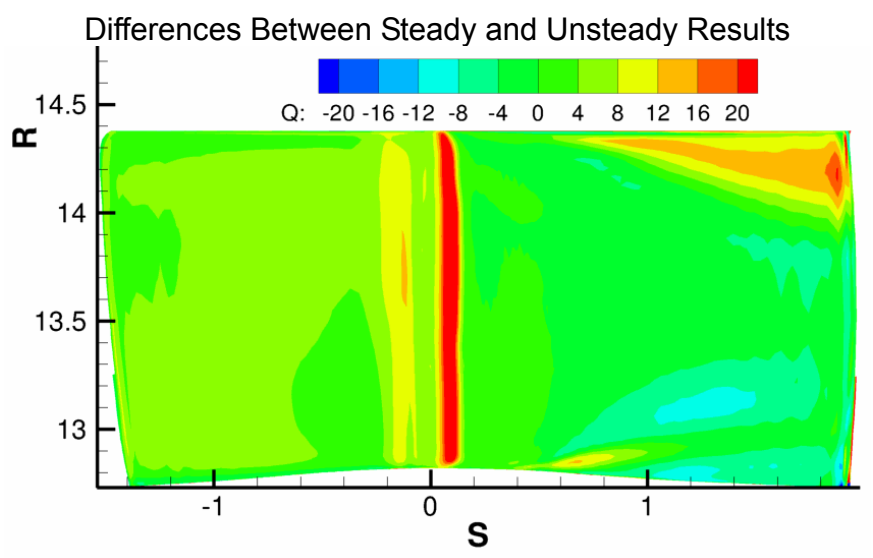

Figure 10.-Percent difference between the unsteady average and steady computation of heat flux.

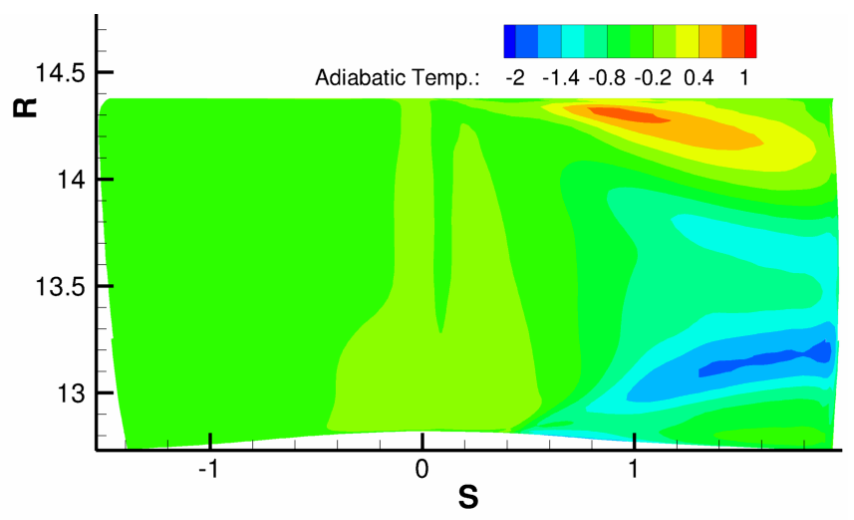

Figure 11.-Percent difference between the unsteady average and steady adiabatic wall temperature.

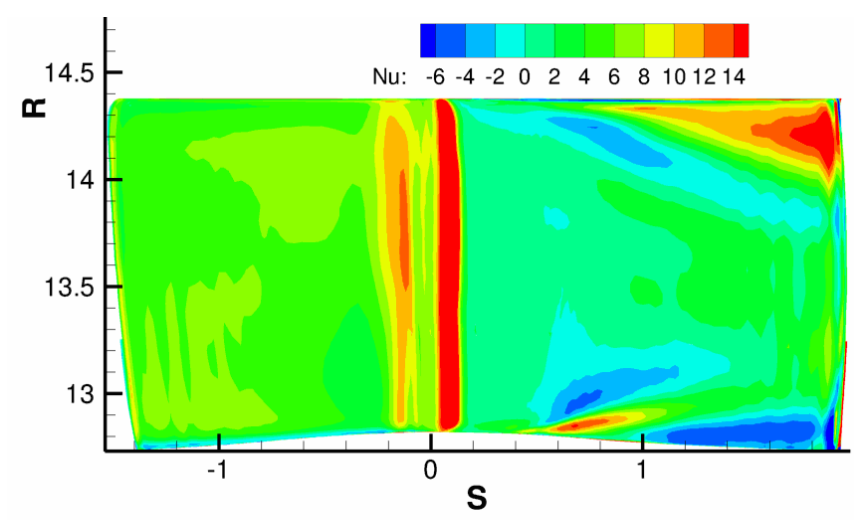

Figure 12.-Percent difference between the unsteady average and steady heat transfer coefficient.

heat transfer coefficient of equation (4) are presented in figures 13 to 15 . Only the condition with both wakes are presented. The adiabatic wall temperature distribution is remarkably flat and suggests a lower recovery temperature as compared to the blade surface. The patterns of heat flux distribution are as described for example in references 12 and 13. The heat transfer coefficients are elevated compared to the blade surface. 
Q: 225270315360405450495540585630675

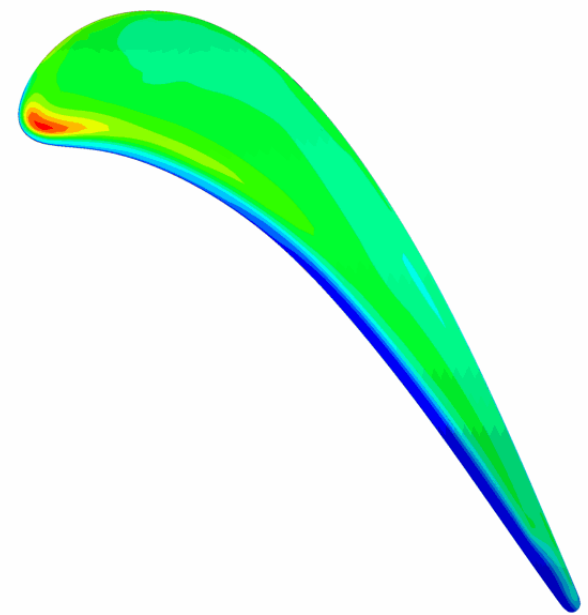

Figure 13.-Average of unsteady heat flux.

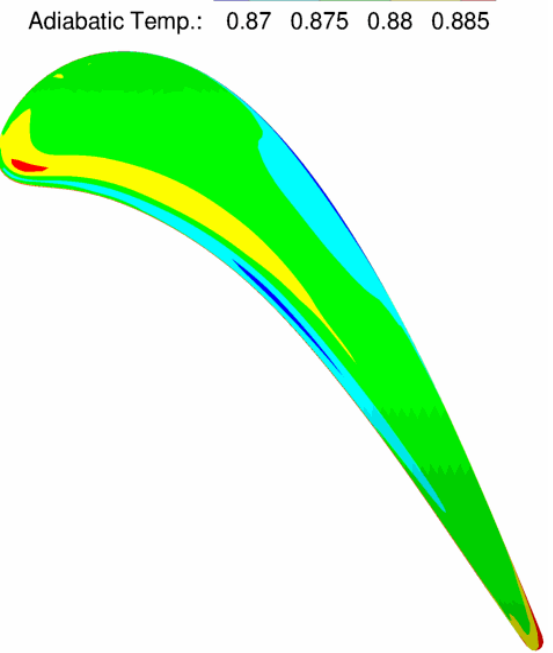

Figure 14.-Average of unsteady adiabatic wall temperature.

Nu: 1000140018002200260030003400

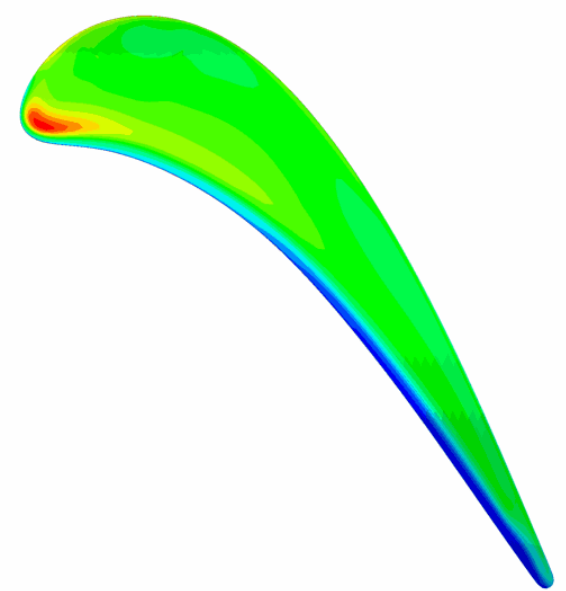

Figure 15.-Average of unsteady heat transfer coefficient (Nusselt number).

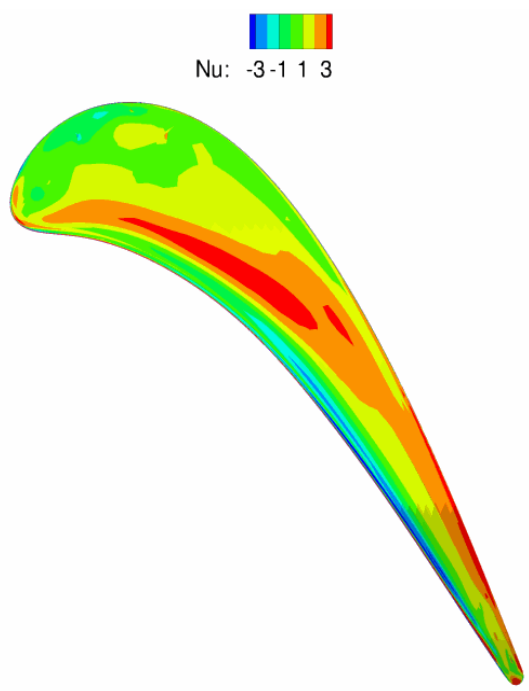

Figure 16.-Percent deviation from average of unsteady Nusselt number.

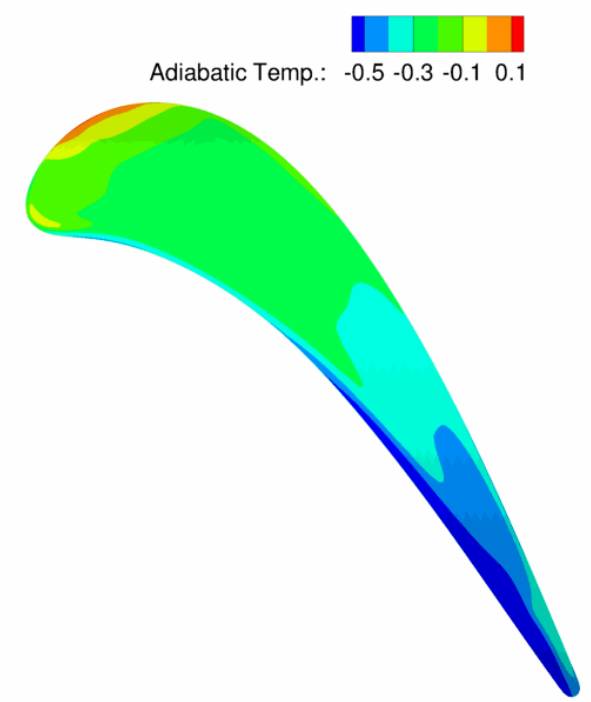

Figure 17.-Percent deviation from average of unsteady adiabatic wall temperature.

\section{Steady Distribution}

Figures 16 and 17 show the percent difference between the average of the unsteady and steady computations. As in reference 1 the differences are quite small. The differences in the heat flux were at most around 4 percent. The difference was mostly positive over the tip surface. The deviation of the adiabatic wall temperature was quite small. Note that all the differences were normalized by the unsteady average values.

\section{Summary and Conclusions}

The question of whether an unsteady RANS analysis would result in a significantly different convective heat transfer coefficient or a steady analysis may be sufficient has been 
addressed here. Rotor blade surface heat transfer coefficient, heat flux and adiabatic wall temperature as influenced by the momentum and thermal wakes behind the vane were computed. This required two separate unsteady or steady computations to be made and the results processed in a phase locked fashion. The wake was simulated using a gust type boundary condition. The adiabatic wall temperature on the suction side near the tip and towards the trailing edge was found to be the highest on the blade surface. This would give rise to higher surface temperatures in this area which is what happens in engines. The unsteady computations of heat transfer coefficient when averaged are generally higher than the steady values for the same area of the blade pressure side by as much as 8 percent. On the suction side, the difference was as high as 20 percent near the trailing edge and near the tip. The net difference was positive on the suction side but, there were negative differences but were caused by a shift. In general, the unsteady average blade surface heat transfer coefficient is higher than the steady computation.

Concerning the tip heat transfer, the maximum difference observed was about four percent in the middle of blade tip.

In general, the following statements may be made about the differences between the unsteady average and steady results:

With regard to heat transfer, the average of the URANS calculation generally produces a larger result than the RANS calculation. The overall difference is roughly 5 percent.

The objective of this work was to determine if such differences would arise and what their relative difference be. It seems likely that the URANS result could generally be more likely to produce a better result than RANS. After all the unsteadiness resolved with URANS is coherent and periodic; this is not the type of unsteadiness that characterizes turbulence and unlikely for a turbulence model to capture.

\section{References}

1. Ameri, Ali A., Rigby, David L., Steinthorsson, E., Heidmann James, Fabian John C., "Numerical Simulation of Unsteady Turbine Blade and Tip Heat Transfer Due to Wake Passing," GT2007-27550.
2. Rao, K.V., Delaney, R.A. and Dunn, M.G., "Vane-Blade Interaction in a Transonic Turbine, II-Heat Transfer," Journal of Propulsion and Power 1994, vol. 10, no. 3, pp. 312-317.

3. M.G. Dunn, C.W. Haldeman, R.S. Abhari, and M.L. McMillan, "Influence of Vane/Blade Spacing on the Heat Flux for a Transonic Turbine," 2000-GT-0206.

4. Michelassi, V., Martelli, F., Deons, R., Arts, T. and Sieverding, C.H., "Unsteady Heat Transfer in Stator-Rotor Interaction by Two-Equation Turbulence Mode," Journal of Turbomachinery vol. 121, Jul. 1999, pp 436-447.

5. Abhari, R.S., Guenette, G.R., Epstein, A.H., and Giles, M.B., "Comparison of Time-Resolved Turbine Rotor Blade Heat Transfer Measurements and Numerical Calculations," Journal of Turbomachinery, vol. 114, Oct. 1992, pp. 818-827.

6. Ameri, A.A., Rigby, D., Heidmann, J. Steinthorsson, E., Fabian, J., "Effects of Unsteadiness Due to Wake Passing on Rotor Blade Heat Transfer," AIAA-2006-3263

7. Denos, R., Sieverding, C.H., Arts, T., Brouckaert, J., Paniagua, G. and Michelassi, V., "Experimental Investigation of the Unsteady Rotor Aerodynamics of a Transonic Turbine Stage," Third European Conference in Turbomachinery, Fluid Dynamics and Thermodynamics (IACA programme), 1999.

8. Chana, Kam S., Hilditch, Mary A., Anderson, James A., "An Investigation of the Effects of Film Cooling in a High-Pressure Aeroengine Turbine Stage," ASME paper GT2005-68564.

9. Wilcox, D.C., Turbulence Modeling for CFD, DCW Industries, Inc., La Canada, CA, 1994.

10. Ameri, A.A., E. Steinthorsson, D. Rigby, "Effect of Squealer Tips on Rotor Heat Transfer and Efficiency," ASME Journal of Turbomachinery, vol. 120, no. 4, pp. 753-759, 1998.

11. Halila, E.E. and Lenahan, D.T., and Thomas, L.L., "Energy Efficient Engine, High Pressure Turbine Test Hardware Detailed Design Report," NASA CR-167955, 1982.

12. Ameri, A.A., E. Steinthorsson, D. Rigby, "Effect of Tip Clearance and Casing Recess on Heat Transfer and Stage Efficiency in Axial Turbines," ASME Journal of Turbomachinery, vol. 121, no. 4, pp. 683-693, Oct. 1999.

13. Ameri, A.A. and Bunker, R.S., 2000, "Heat Transfer and Flow in the First Stage Blade Tip of a Power Generation Gas Turbine, Part 2: Analytical Results, ASME Journal of Turbomachinery, vol. 122, pp. 272-277.

14. Ali. A. Ameri, "Heat Transfer and Flow on the Blade Tip of a gas Turbine Equipped with a Mean-Camberline Strip," ASME Journal of Turbomachinery, vol. 123, no. 4. pp. 704-708, Oct. 2001. 


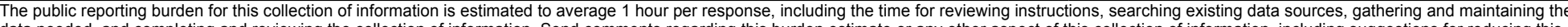

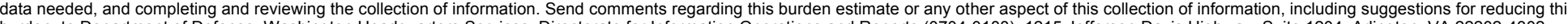

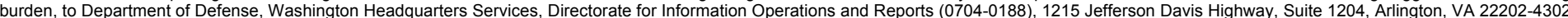

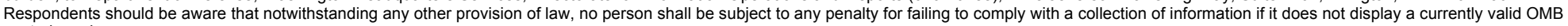
control number.

PLEASE DO NOT RETURN YOUR FORM TO THE ABOVE ADDRESS.

\section{REPORT DATE (DD-MM-YYYY) \\ 2. REPORT TYPE \\ 3. DATES COVERED (From - To)}

01-07-2008

Technical Memorandum

\section{TITLE AND SUBTITLE}

Unsteady Analysis of Blade and Tip Heat Transfer as Influenced by the Upstream Momentum and Thermal Wakes

\section{5a. CONTRACT NUMBER}

5b. GRANT NUMBER

5c. PROGRAM ELEMENT NUMBER

5d. PROJECT NUMBER

5e. TASK NUMBER

5f. WORK UNIT NUMBER

WBS 984754.02.07.03.16.06

\section{PERFORMING ORGANIZATION}

REPORT NUMBER

E-16520

National Aeronautics and Space Administration

John H. Glenn Research Center at Lewis Field

Cleveland, Ohio 44135-3191

9. SPONSORING/MONITORING AGENCY NAME(S) AND ADDRESS(ES)

National Aeronautics and Space Administration

Washington, DC 20546-0001

\section{DISTRIBUTION/AVAILABILITY STATEMENT}

Unclassified-Unlimited

Subject Category: 34

Available electronically at http://gltrs.grc.nasa.gov

This publication is available from the NASA Center for AeroSpace Information, 301-621-0390

\section{SUPPLEMENTARY NOTES}

\section{ABSTRACT}

The effect of the upstream wake on the blade heat transfer has been numerically examined. The geometry and the flow conditions of the first stage turbine blade of GE's E3 engine with a tip clearance equal to 2 percent of the span was utilized. Based on numerical calculations of the vane, a set of wake boundary conditions were approximated, which were subsequently imposed upon the downstream blade. This set consisted of the momentum and thermal wakes as well as the variation in modeled turbulence quantities of turbulence intensity and the length scale. Using a one-blade periodic domain, the distributions of unsteady heat transfer rate on the turbine blade and its tip, as affected by the wake, were determined. Such heat transfer coefficient distribution was computed using the wall heat flux and the adiabatic wall temperature to desensitize the heat transfer coefficient to the wall temperature. For the determination of the wall heat flux and the adiabatic wall temperatures, two sets of computations were required. The results were used in a phase-locked manner to compute the unsteady or steady heat transfer coefficients. It has been found that the unsteady wake has some effect on the distribution of the time averaged heat transfer coefficient on the blade and that this distribution is different from the distribution that is obtainable from a steady computation. This difference was found to be as large as 20 percent of the average heat transfer on the blade surface. On the tip surface, this difference is comparatively smaller and can be as large as four percent of the average.

\section{SUBJECT TERMS}

Turbine; Heat transfer; Wakes; Unsteadiness

\begin{tabular}{|l|l|l|l|}
\hline \multicolumn{2}{|l|}{$\begin{array}{l}\text { 16. SECURITY CLASSIFICATION OF: } \\
\text { 17. LIMITATION OF } \\
\text { ABSTRACT }\end{array}$} \\
\begin{tabular}{|l|l|} 
a. REPORT \\
U
\end{tabular} & $\begin{array}{l}\text { b. ABSTRACT } \\
\text { U }\end{array}$ & $\begin{array}{l}\text { c. THIS } \\
\text { PAGE } \\
\text { U }\end{array}$ & UU \\
\hline
\end{tabular}

10. SPONSORING/MONITORS
ACRONYM(S)
NASA
11. SPONSORING/MONITORING
REPORT NUMBER
NASA/TM-2008-215257; GT2008-51242

Ali, Ameri, A.; Rigby, David, L.; Steinthorsson, Erlendur; Heidmann, James, D.; Fabian,

( 

